\title{
A comparison of AC and HVDC options for the connection of offshore wind generation in Great Britain
}

\author{
D. Elliott, K.R.W. Bell, Member IEEE, S.J. Finney, R. Adapa, Fellow IEEE, \\ C. Brozio, Member IEEE, J. Yu and K. Hussain
}

\begin{abstract}
This paper presents a comparison of two forms of cable connection of a distant offshore wind farm to a transmission system: AC and HVDC. The requirements of relevant industry standards in Great Britain (GB) that drive a connection design and, hence, its cost are highlighted along with an analysis of the ways in which $\mathrm{AC}$ cable connections might be made to comply while facilitating export of active power. Dynamic studies investigating responses to grid-side short circuit faults show that, in the particular scenarios studied, an AC connection of a wind farm in the place of a large synchronous generator is marginally detrimental while an HVDC connection is beneficial. A comparison of costs shows that the cross-over distance at which HVDC is cheaper than $\mathrm{AC}$ for wind farms of different sizes occurs at longer distances than have hitherto commonly been assumed, and $\mathrm{AC}$ connections benefit from reactive compensation not only at the point of common coupling and wind farm end but also at the connection mid-point.
\end{abstract}

Index Terms - wind energy, cables, HVDC, reactive power, voltage control, power system stability, power system economics.

\section{INTRODUCTION}

A large proportion of new wind farms in Britain seeking transmission connections will be offshore [1] and so require use of undersea cables. Moreover, many of them will be quite distant from the nearest existing transmission route into which they might be connected. At long distances, a HVDC connection from the wind farm itself to the main interconnected transmission system (MITS) becomes a costcompetitive alternative to a conventional AC connection, though HVDC might also be considered for onshore connections that require the use of cables for local planning reasons. In [2], the distance at which HVDC connection of an offshore wind farm becomes cheaper than an AC cable solution is described as being conditional on a number of factors including average wind speed, discount rate and wind

The work described in this paper was supported by the Electric Power Research Institute (EPRI), as part of project 3002000863on "Transmission requirements for off-shore wind integration".

Douglas Elliott is with Siemens Wind Power, Glasgow, UK (email: douglas.elliott@siemens.com ). Keith Bell and Steve Finney are with the University of Strathclyde, Glasgow, UK (email: keith.bell@strath.ac.uk and Stephen.finney@strath.ac.uk respectively). Ram Adapa is with EPRI, Palo Alto, USA (email: RADAPA@epri.com ). Cornel Brozio and James Yu are with Scottish Power Energy Networks, Glasgow, UK (email: Cornel.Brozio@ScottishPower.com and james.yu@scottishpower.com ). Khadim Hussain is with National Grid Electricity Transmission, Warwick, UK (email: Khadim.Hussain@nationalgrid.com ). farm size with results ranging between around $83 \mathrm{~km}$ (for a 400MW wind farm with an average wind speed of $8 \mathrm{~m} / \mathrm{s}$ ) and around $95 \mathrm{~km}$ (for a $1000 \mathrm{MW}$ with an average wind speed of $11 \mathrm{~m} / \mathrm{s})$. In [3], dependency of the 'break-even' distance is explored in respect of whether investment in both the connection and the wind farm is undertaken by the same party, in which case the distance is reported as being $35 \mathrm{~km}$ for a $300 \mathrm{MW}$ wind farm, or two different parties in which case it is $80 \mathrm{~km}$. Meanwhile, [4] and [5] highlight the importance of losses in the evaluation..

It has been commonly assumed that HVDC is the only practical option for cable connections above a certain distance [3] and a number of HVDC connections of offshore wind farms are reported as being planned for commissioning in 2014 or 2015 [6][7]. However, anecdotal evidence suggests that wind farm developers are now hesitant to invest in what they still regard as a relatively unproven technology, namely voltage source converters (VSC) employed in a challenging offshore environment and connected to an offshore AC hub that collects power only from wind turbines. They have therefore sought more comprehensive evaluation of the costs and benefits of HVDC compared with $\mathrm{AC}$ and are considering an AC solution at significantly longer distances than [2] or [3] suggested would be economic. Precedent for using long AC submarine transmission cables has been set by the oil industry and the construction of interconnections between different, otherwise islanded, power networks [8]-[10]. These include three-phase AC cables at line voltages of $145 \mathrm{kV}$ and up to 162 $\mathrm{km}$ in length. Moreover, consideration is being given to ways in which the problems associated with long AC cables might be overcome, including use of mid-point compensation to reduce voltages and losses [11]. Meanwhile, one of the first planned HVDC connections of an offshore wind farm, BorWin1, was originally expected to be operational in 2009 but is, as of November 2014, reported by ABB to be planned for commissioning in 2015 [6] with a number of problems having been reported including overcurrent in a filter, a fire and "dirty electricity' affecting the substation" [12].

This paper presents a comparison of AC and HVDC transmission for the point-to-point connection of offshore wind farms to the transmission system in Great Britain (GB) in order to establish the most economic form of connection for different sizes of wind farm with different lengths of cable connection. This is firstly determined by the functional 
requirements for the connection and these are set by relevant industry codes that define minimum performance capabilities.

Not least because of the high capacitance of long AC cables, a particular focus of the study reported here is in respect of voltage control and reactive power. For example, while it is well known that $\mathrm{AC}$ cables tend to generate reactive power, the requirements of the STC can be satisfied at the point of connection to the MITS by installation of appropriate reactive compensation. For a valid comparison of the cost of the AC option with that of HVDC, the cost of this reactive compensation should be included along with that of power losses. However, other performance characteristics, while not required by any of the codes, might be inherently provided by certain classes of equipment and prove valuable to operation of the system, e.g. the flexibility of VSC, not least in responses to faults and provision of reactive power. These characteristics are also important and have been investigated in this study in respect of contributions to system stability.

The next section of this paper briefly reviews the main codes that set the functional requirements for connection of offshore wind farms in British waters to the GB MITS. Then, some case studies are outlined followed by presentation of results of steady state and dynamic analyses, the latter of which compares responses to system faults when an offshore wind farm is connected either via an AC cable or via HVDC VSC. Then, some comparisons of the economics of different connection options are presented for different sizes of wind farm at different distances from shore along with some relevant regulatory issues followed by conclusions.

\section{REQUIREMENTS SET BY RELEVANT CODES}

There are three documents that detail the connection requirements for wind farms in Britain: The Grid Code [13]; the System Operator, Transmission Owner Code (STC) [14] which manages the relationship between different transmission owners (TOs) and between a TO and the system operator; and the Security and Quality of Supply Standard (SQSS) [15]. Within these documents there are four particular areas of relevance to the connection of a wind farm via a long transmission link: power factor capability at the point of common coupling (PCC) between the transmission link and the MITS; voltage tolerance band at all points in the network; design requirements to comply with loss of in-feed risks; and the capability for the voltage at each node and the generation in the system to recover following the clearance of a fault.

The Grid Code governs the interface between the generator (wind farm) and the immediate transmission link. Under GB regulatory arrangements, the transmission link between an offshore wind farm and the MITS will be maintained by an Offshore Transmission Owner (OFTO). The interface between the latter's assets and the MITS is governed by the STC.

\section{A. Power factor and voltage control requirements}

In order to support the voltage at the interface point between the wind farm transmission link and the MITS there must be the capability for the power factor to be controlled over a minimum range of 0.95 lagging to 0.95 leading. This requirement is valid over a certain active power transfer range [14]. A functional performance specification is also set out dictating the required capability for "continuous changes to the reactive power supplied" at the interface point between an offshore network and the onshore network. The associated voltage control system is required to be able to start a response to interface point voltage step changes within $0.2 \mathrm{~s}$ of the application of a step, be capable of operating between $95 \%$ and $105 \%$ of the nominal voltage and have a slope characteristic between reactive power and voltage of between $2 \%$ and $7 \%$ within the range of reactive power capability. It should also be possible for the set point to be changed within 2 minutes of receiving an instruction from the National Electricity Transmission System Operator (NETSO). If it is the view of the NETSO that additional voltage control facilities are required for system reasons at the interface point, these will be specified in the Offshore Transmission Owner Construction Agreement. (It may be noted in passing that no such voltage control requirements are defined in the STC at interfaces between onshore networks).

In addition to these requirements, the voltage at all points within the electrical network should be within limits during normal operation. Two sets of steady state voltage limits (applying to post-transient conditions) are defined in the SQSS: planning limits and operating limits (Table I). The former are those that should be adhered to when designing the system whereas the latter are the final values for system operation. The former are tighter than the latter in order to provide some flexibility against a range of possible operating conditions. Limits are also defined with respect to step changes that occur as a result of switching operations within the network.

\begin{tabular}{|c|c|c|c|c|}
\hline \multicolumn{5}{|c|}{ PLANNING AND OPERATION TIMESCALES [15] } \\
\hline $\begin{array}{c}\text { System } \\
\text { nominal } \\
\text { voltage }\end{array}$ & $\begin{array}{l}\text { Planning } \\
\text { timescale } \\
\text { voltage } \\
\text { minimum } \\
\end{array}$ & $\begin{array}{c}\text { Planning } \\
\text { timescale } \\
\text { voltage } \\
\text { maximum }\end{array}$ & $\begin{array}{c}\text { Operational } \\
\text { timescale } \\
\text { voltage } \\
\text { minimum } \\
\end{array}$ & $\begin{array}{c}\text { Operational } \\
\text { timescale } \\
\text { voltage } \\
\text { maximum }\end{array}$ \\
\hline $400 \mathrm{kV}$ & $\begin{array}{l}380 \mathrm{kV} \\
(95 \%)\end{array}$ & $\begin{array}{c}410 \mathrm{kV} \\
(102.5 \%)\end{array}$ & $360 \mathrm{kV}(90 \%)$ & $\begin{array}{l}420 \mathrm{kV} \\
(105 \%)\end{array}$ \\
\hline $275 \mathrm{kV}$ & $\begin{array}{l}248 \mathrm{kV} \\
(90 \%)\end{array}$ & $\begin{array}{l}289 \mathrm{kV} \\
(105 \%)\end{array}$ & $248 \mathrm{kV}(90 \%)$ & $\begin{array}{l}303 \mathrm{kV} \\
(110 \%)\end{array}$ \\
\hline $132 \mathrm{kV}$ & - & $\begin{array}{l}139 \mathrm{kV} \\
(105 \%)\end{array}$ & $119 \mathrm{kV}(90 \%)$ & $\begin{array}{l}145 \mathrm{kV} \\
(110 \%)\end{array}$ \\
\hline
\end{tabular}

\section{B. Fault ride-through capability}

Following the occurrence of a fault on the MITS with a duration of up to $140 \mathrm{~ms}$, the wind farm transmission link is required to remain connected to the rest of the system without the tripping of any plant associated with it. This must be achieved for a close-up solid three phase fault or any unbalanced short circuit fault. During the fault period the transmission link should generate maximum reactive current without exceeding equipment current ratings and, following the clearance of the fault by the operation of protection within the MITS and the restoration of the interface point voltage, the transmission link is required to restore its active power transfer to within $90 \%$ of pre-fault levels within 0.5 seconds. In response to a voltage dip with a duration longer than $140 \mathrm{~ms}$ the transmission link should remain connected and generate 
maximum reactive power capability while the interface point voltage is at least $15 \%$ at $140 \mathrm{~ms}$ from fault inception, rising to $80 \%$ at $1.2 \mathrm{~s}$ and $90 \%$ after 3 minutes, and restore its active power transfer to within $90 \%$ of pre-fault levels within 1 second of the interface voltage being restored [13].

\section{Loss of in-feed requirements}

The electrical design of a wind farm transmission link must comply with requirements set out in the SQSS with regard to limiting the loss of in-feed risks to the system [15]. There are two main design requirements which apply to different prefault operational requirements: 'normal' in-feed loss risk and 'infrequent' in-feed loss risk. In the former case, a single secured event should not result in a generation in-feed loss of more than $50 \%$ of the registered generation capacity or $1000 \mathrm{MW}$, whichever is smaller. Infrequent in-feed loss risk refers to occasions where the transmission link is operating in a degraded state due to a previous fault or maintenance outage. In such a case, no more than $1320 \mathrm{MW}$ of in-feed should be lost in response to a fault. Both 'normal' and 'infrequent' requirements must be considered when determining the number of transformers or converters. However, due to the potential cost of an additional cable, the requirement for a cable circuit is less onerous: following an outage of a cable due to a fault or maintenance, no more than 1320MW of generation in-feed should be lost.

\section{CASE STUDIES - CONNECTION OF OFFSHORE WIND FARMS OF DIFFERENT SIZES AND DISTANCES FROM SHORE}

In order to focus on the comparison between $\mathrm{AC}$ and HVDC technology options, similar basic connection designs have been considered in each case, based on a single SQSS compliant connection design placed in the public domain by National Grid Electricity Transmission (NGET) [16]. From that common starting point of an offshore wind farm connection, steady state and dynamic analyses have been carried out to identify ways in which the requirements of the Grid Code and the STC might be satisfied in each case, and then to perform an economic analysis of those broadly compliant options.

The bases for both steady state and dynamic analyses were as shown in Figs. 1 and 2 in respect of AC and HVDC connections respectively. Studies have been undertaken for 250MW, 500MW, 1000MW and 1500MW wind farms with different cable connection lengths. In each AC case, the connection is based on a suitable number of 350MVA threecore cables, chosen for use as it is the three-core submarine cable with greatest capacity that is in production and available from a number of suppliers [16]. Furthermore, in the analyses, the following assumptions have been made:

- active power only is fed into the distant, wind farm, end of the transmission cable.

- the cable capacity is de-rated by $12 \%$ to account for thermal constraints around the entry of the cable to the jtubes [16].

With $220 \mathrm{kV}, 350 \mathrm{MVA}$ cables derated to around 300MVA, the offshore connection requirements of the SQSS indicate the use of 1 cable for a 250MW wind farm, 2 for $500 \mathrm{MW}, 4$ for $1000 \mathrm{MW}$ and 6 for $1500 \mathrm{MW}$.

For the HVDC case, for studies of faults on the AC system, only the converter at the PCC needs to be represented.

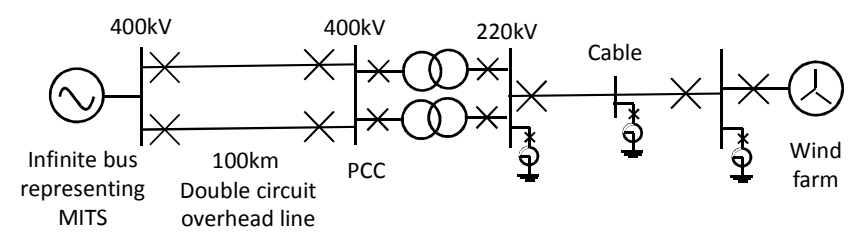

Fig. 1 Test network used to simulate close-up and distant faults with AC transmission and either DFIG or FRC wind turbines within the wind farm. Possible locations of shunt reactors are shown.

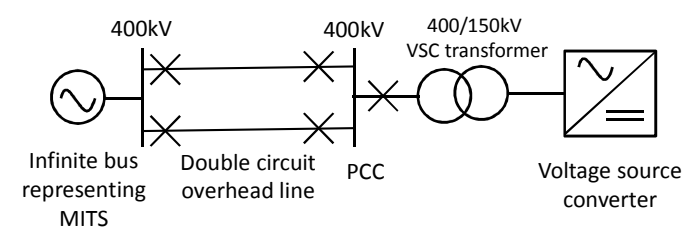

Fig. 2 Test network used to simulate close-up and distant fault with HVDC transmission (represented by the VSC terminal) for a wind farm connection

\section{STEADY STATE ANALYSIS}

In this section, the reactive power production characteristics of the AC cable connections are investigated over different lengths. By modelling the cable as four equal sections, denoted Subsea cable sections (SSC) 1-4 where SSC1 is that closest to the PCC, with three intermediary connection points, denoted Subsea buses (SSB) 1-3 and the cable parameters distributed equally, it can be ensured that the cable loading (both active and reactive power) does not exceed $100 \%$ of the continuous rating as its length is increased and that voltage rise is not excessive. The application of mechanically switched reactive compensation at various locations is investigated in order that Grid Code power factor requirements can be met at the interface point between the cable and the MITS (the PCC) and so that the voltage profile throughout the cable stays within its rating [13]. This will allow an indication of the required compensation capacity at each point to be given.

For the purpose of the steady state analysis, the grid end of the connection is directly connected to an infinite bus, fixing the voltage at this point at $1 \mathrm{pu}$.

\section{A. Single cable connection}

To illustrate the issues, the case of a single cable is considered first. In Fig. 3, the amount of reactive power produced by the cable as its length is increased is measured at the PCC. It can be seen that, relative to the cable's continuous thermal rating, the amount of capacity available for export of active power from the wind farm decreases as the cable length increases and reaches zero at $120 \mathrm{~km}$. Fig. 4 shows the rise in voltage along the cable's length.

To meet the Grid Code connection requirements, there must be the capability to provide a minimum of 0.95 power factor leading and lagging at the PCC. Fig. 5 shows the quantities of required capacitive and inductive reactive compensation to meet the power factor requirements at the PCC. Although the 
cable produces reactive power, to ensure that 0.95 leading power factor can be achieved for short cable lengths, it can be seen from Fig. 5 that extra capacitance is required at the PCC for the shortest cable length. At longer distances, inductive compensation must also be added with sufficient capacity to absorb the maximum amount of reactive power produced by the cable plus enough extra to consume reactive power from the grid in compliance with the 0.95 lagging capability.

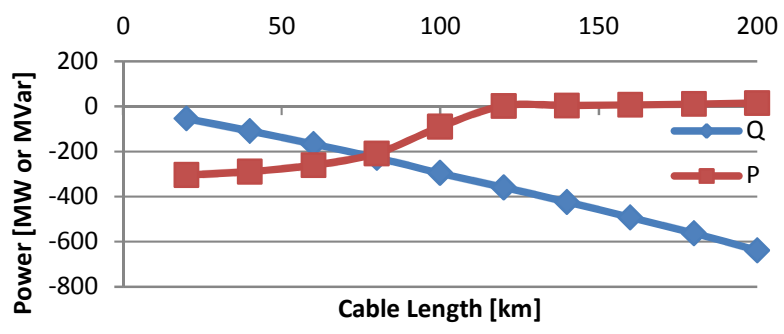

Fig. 3: Power export measured at the grid interface point for wind farm production of $308 \mathrm{MW}$ and unity power factor. (Negative values indicate export from wind farm to grid)

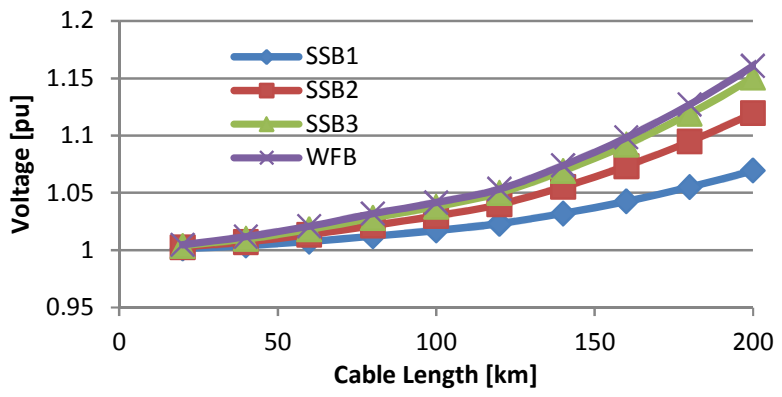

Fig. 4: Voltages at different points along the cable as overall length is increased, no reactive compensation installed

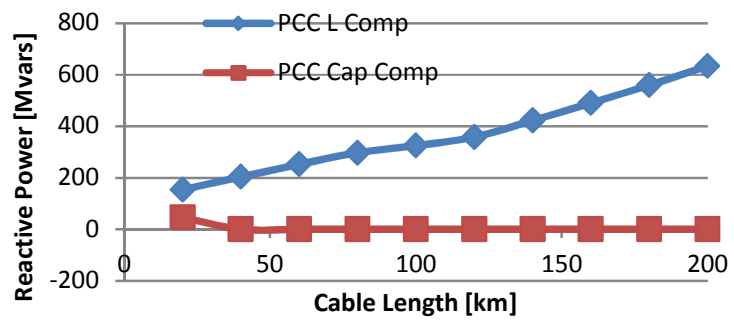

Fig. 5: Inductive and capacitive reactive compensation required at the PCC to comply with the Grid Code

\section{B. Location of reactive compensation}

In order to increase the amount of active power that can be transferred over longer cable lengths, reactive compensation can be added at the wind farm end of the cable in addition to the compensation at the grid end, provided the cable rating is not exceeded. Fig. 6 shows the loading of the different sections of cable as length increases, before compensation is added at the wind farm bus (WFB). It is clear that the first section of the subsea cable nearest the grid end, SSC1, has the highest loading and that SSC4 is the least loaded. This is because SSC1 is exporting the reactive power produced by the whole cable as well as the active power transfer. By adding reactive compensation at the wind farm end of the cable the vacant capacity of SSC4 can be used by some of the reactive power therefore freeing up capacity in $\mathrm{SSC} 1$, increasing the overall active power transfer capacity.

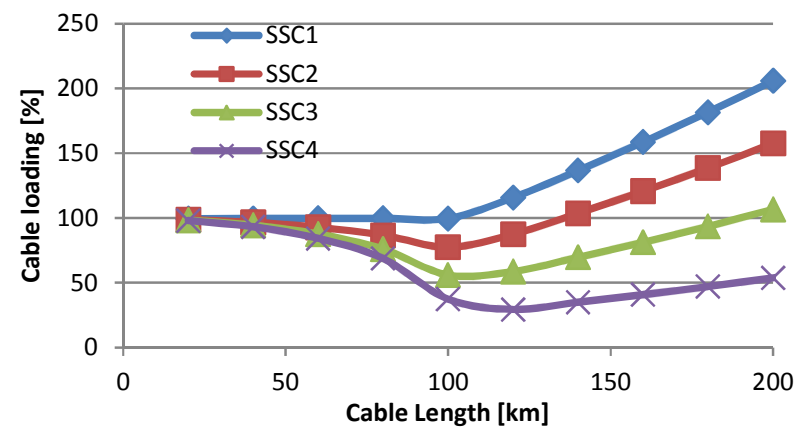

Fig. 6: Loading of the different cable sections as a percentage of the overall cable rating, where no reactive compensation is a present and the wind farm neither absorbs nor produces reactive power

It is demonstrated in Fig. 7 that adding reactive compensation at the wind farm end of the cable splits the reactive power produced by the cable between both ends, allowing greater quantities of active power to be transferred over longer distances, compared to Fig. 6. The limitation to the amount of reactive compensation that can be added at the wind farm end is the amount of vacant capacity in cable section 4 . When the cable length becomes greater than $150 \mathrm{~km}$, the export of reactive power for compensation takes precedence over the transfer of active power. After $200 \mathrm{~km}$ the whole cable capacity is taken up by the export of reactive power.

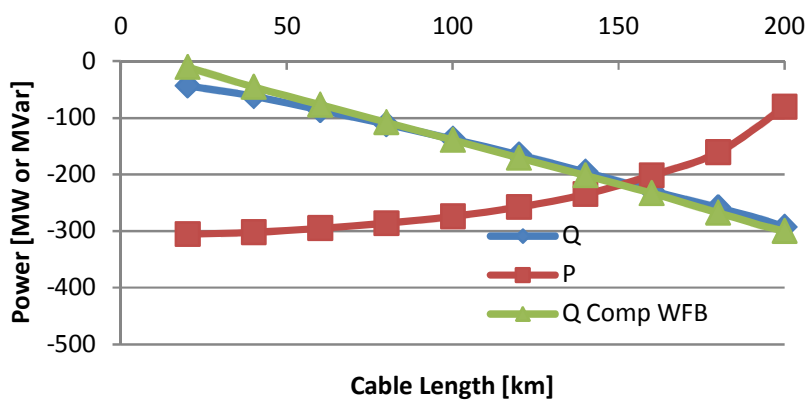

Fig. 7: Active and reactive power exported through the grid end of the cable and the reactive power absorbed by compensation at the wind farm bus (WFB) as cable length increases

A closer look at the results of adding compensation at the wind farm end reveals that when cable sections SSC1 and $\mathrm{SSC} 4$ are operating at maximum thermal capacity, SSC2 and SSC3 have spare capacity. To extend the active power transfer capability of the cable over longer distances, utilisation of this vacant capacity is critical. This can be achieved by adding reactive compensation at the cable mid-point. The authors' understanding is that such an action is actively being considered by a number of developers in the UK, e.g. the Smart Wind consortium which is developing the Hornsea zone in the North Sea has indicated that it is under consideration and the Crown Estate has suggested that it can be competitive [17][18]. The Horns Rev B wind farm in Denmark has also set a precedent for such an arrangement by employing a $100 \mathrm{~km}$ AC cable connection with a compensating reactor near the cable mid-point [11] although the cable connection in this case 
consists of $42 \mathrm{~km}$ of subsea cable and $58 \mathrm{~km}$ of onshore cable and the mid-point compensating reactor is located onshore.

The addition of reactive compensation at SSB2, in equal quantity to that at the wind farm end of the cable, divides the cable reactive power production in three. The impact of this can be observed in Fig. 8 where the reactive power exported from the cable at the grid end is approximately equal to the reactive power absorbed by the compensation at the mid-point and wind farm end of the cable. Comparison of Fig. 8 with Figs. 3 and 7 shows the improvement of the active power transfer capability over long distances.

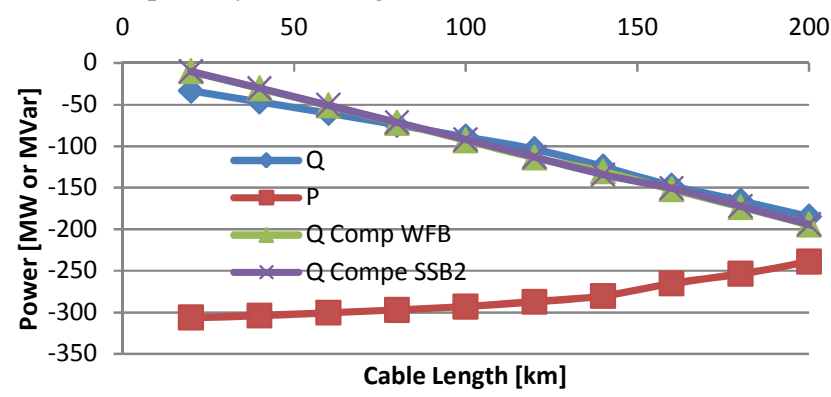

Fig. 8: Active and reactive power exported from the cable at the grid end, and the amounts of reactive power compensation included at the cable mid-point and at the wind farm bus

\section{Other considerations for installation of reactive compensation}

In addition to the power factor, voltage and cable rating requirements there are a number of other issues that must be considered. These include the maximum allowable voltage step change following a switching operation and the electrical location of reactive compensation.

\section{1) Maximum allowable sizing of reactors}

The SQSS maximum step change limit dictates the maximum size of single reactor used in the system. A planned maximum voltage deviation of $6 \%$ is allowable following a switching operation [13]. For example, in the network used in the above studies with $160 \mathrm{~km}$ cable length, the maximum reactor size that can be switched at the distant end of the cable is approximately $100 \mathrm{MVar}$, i.e. the required reactive compensation of $150 \mathrm{MVar}$ must be provided in at least two independent steps not larger than 100MVar.

\section{2) Connection of reactive compensation}

The connection of the reactive compensation is important when considering the voltage rise along the cable in the situation where the circuit breaker at the distant end of the cable is open. If the cable voltage does not remain within the limits when this circuit breaker is open, the reactive compensation must be directly coupled to the end of the cable before connection to the WFB so that it can be energised at the same time as the cable. Otherwise the reactive compensation could be connected to the wind farm busbar. For example, with a cable length of $160 \mathrm{~km}$ the reactive compensation must be directly coupled to the cable, otherwise the voltage at the distant end of the cable will reach 1.09pu when the WFB cable circuit breaker is open.

\section{ANALYSIS OF DYNAMIC RESPONSES}

An AC connection of an offshore wind farm and an HVDC connection will be materially different from each other in the way they respond to faults and, as a consequence, would be regarded by the system operator as more or less beneficial.

The purpose of the studies reported here is not to provide an exhaustive examination of the comparative performance but rather to illustrate some issues pertinent to the GB context and, in particular, the impact on voltage compliance and transient stability. The scenario used is one of exports of power from Scotland into England, a situation known to be limited by transient stability considerations.

\section{A. Stability assessment scenario}

A model of the GB transmission system has been implemented in DIgSILENT PowerFactory [19] and is based on the anticipated characteristics of the generation and transmission system in 2020. The generation is dispatched in such a way that the initial net power export from Scotland in the north to England in the south in $4300 \mathrm{MW}$. This boundary is referred to in [1] as boundary B6 and features two double circuit overhead lines (Fig. 9). A permanent short circuit fault is applied to the west coast double circuit leading to its disconnection. This causes the power that was initially flowing down the western corridor to transfer to the east. The modelled initial condition is set-up so that when this contingency occurs, the system remains stable and settles to a new steady state with a voltage complying with the SQSS, though only just with the post-fault steady state voltage being close to the minimum of 0.95 defined in [15]. This scenario forms the base case used for comparison. In it, a $1200 \mathrm{MW}$ thermal power station is operating at the northern end of the eastern connector, referred to hereafter as location A.

Two further scenarios are introduced for comparison in which the thermal power station's output at A is replaced by an equivalent output from an offshore wind farm: 1 . with the wind farm using an $\mathrm{AC}$ cable connection including minimum reactive compensation identified from steady state analysis to comply with the requirements of the SQSS, Grid Code and STC; 2 . with the wind farm using an HVDC cable connection. These connections are illustrated in Figs. 1 and 2 respectively with, in both cases, the $100 \mathrm{~km}$ double circuit overhead line and infinite bus replaced by a full model of the GB transmission system as it is expected to be in 2020 [1].

\section{B. Dynamic modelling of HVDC link}

In order to investigate the fault response when the thermal power station is replaced by a HVDC connected wind farm a model of the shore end VSC was developed. The response of a HVDC link to a grid fault is entirely dictated by the behaviour of the grid end VSC as it has the capability to control both its active and reactive power throughput with high bandwidth. Therefore it is not necessary to model the wind farm in detail; the wind farm power input to the HVDC link is represented in the transient stability assessment by a constant power input from the wind farm to the DC link capacitance. 


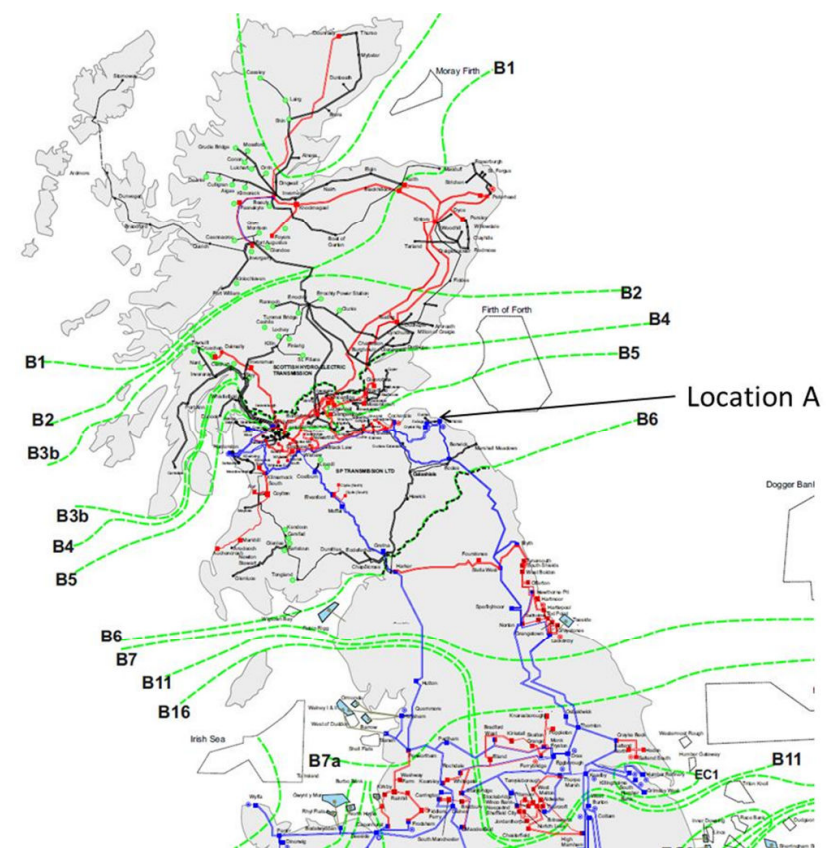

Fig. 9: test case for assessment of dynamic responses: Northern GB [1]

The VSC model developed is an average model and as such uses ideal controllable voltage sources to replicate the output voltage of the converter. Key to the dynamics of the VSC is the control algorithm. The algorithm that has been implemented uses DQ current control to regulate the output current of the converter by controlling its output voltage in relation to the voltage of the grid it is connected to. Included within this controller in addition to the current controller is a Phase Locked Loop to synchronise the converter output to the grid and two outer control loops which provide the references to the inner DQ current controller. These loops act to control the $\mathrm{AC}$ voltage at the terminals of the converter by regulating its reactive current output and the HVDC link voltage by regulating its active current output, both to a predefined constant reference. By controlling the DC link voltage to a particular reference the VSC active power output will track the power input from the wind farm.

Also included in the control algorithm is a current limit feature which primarily acts to ensure that the current rating of the converter is not exceeded, but in doing so gives precedence to outputting reactive current over active current. This means that in the event of a grid fault where the AC voltage control loop asks for an increased amount of reactive current to be fed into the grid to support the voltage, the active current will be curtailed and, if necessary, the full current rating can be output as reactive current. A further loop is also included which will curtail the input power to the HVDC link where the active power output of the converter is reduced therefore preventing the DC voltage from exceeding its rating.

\section{Stability assessment results}

For the western double circuit fault, angular stability is maintained for critical large synchronous generators in both wind farm cases. However, while both responses are acceptable (plots are omitted here simply due to space limitations), the HVDC connection case offers a moderate improvement in damping.

Aside from angular stability, it should also be verified that the post-fault steady state voltage is within limits throughout the system. It can be seen from Figs. 10 and 11 that the HVDC connection achieves this but the AC connection does not. Notwithstanding the STC's stipulation that a 'continuous' voltage regulation capability is required at the interface between the offshore network and the MITS, compliance with the steady state voltage limit could be achieved by, post-fault, switching out a bank of shunt reactance that had been installed to compensate the cable's gain. This is shown in Fig. 12 where the switching action takes place at $5 \mathrm{~s}$.

\section{Other dynamic characteristics that should be considered}

A basic requirement in respect of any generation connection is that the generation can 'ride through' any 'credible' transmission system fault. Using the models shown in Figs. 1 and 2, analyses conducted as part of this study but, for brevity, not reported here have shown that this can be achieved for a wind farm connected via HVDC and for both doubly fed induction generator (Type 3) and fully rated converter (Type 4) wind turbines at a wind farm connected via AC.

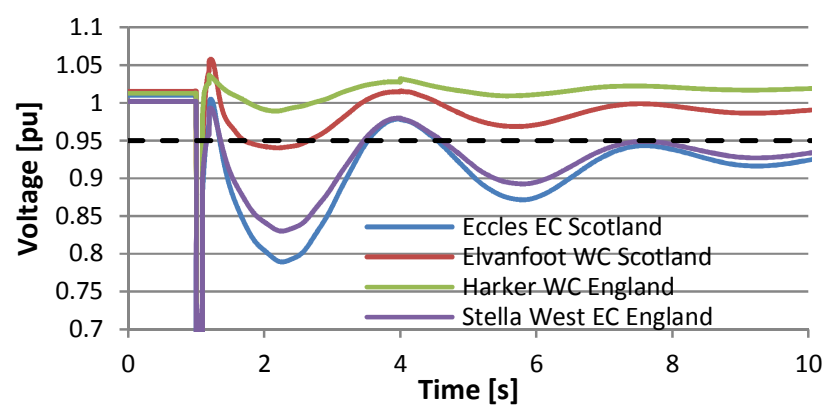

Fig. 10: AC connected wind farm at Location A: voltages at either end of the East Coast (EC) and West Coast (WC) circuits following a WC fault

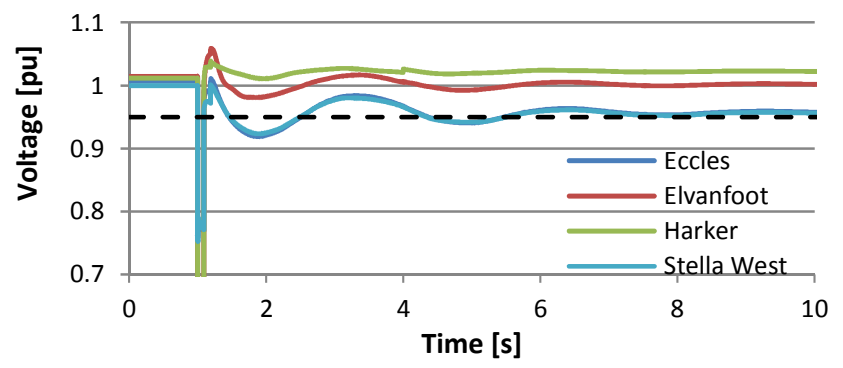

Fig. 11: HVDC VSC connected wind farm at Location A: voltages at either end of the EC and WC circuits following a WC fault

The presence of inductances and capacitances within a power system creates both series and parallel resonant frequency points. The number and frequency of each depends on the size of each lumped or distributed element and their placement with respect to each other [20]. The work reported in [20] suggests possible mitigation measures to low-order resonances in AC cable networks. Both AC and HVDC connections will have an impact on the resonances of the network whether due to the capacitance of the AC cable and the resonant circuit set up between it and the shunt reactors required to regulate the voltage profile over the cable length, 
or any filters required to attenuate switching harmonics produced by a VSC terminal. Switching operations and nonlinear network elements can generate a wide range of high frequency voltage and current components which interact with system resonances to produce oscillations leading to excessive waveform distortion and over-voltages [21]. Damping of oscillations within a power system is often greater for higher frequencies due to the frequency dependence of impedance. The introduction of cables with high capacitance tends to lower the resonant frequencies to levels where damping may be considerably less than before making the occurrence of oscillations more likely [11][22]. Therefore, in addition to the factors that have been determined by both the steady state and dynamic parts of this study, the impacts of each transmission technology on system resonances and harmonic levels should also be taken into consideration when comparing the merits of each technology and mitigation measures taken where necessary, as described in [22].

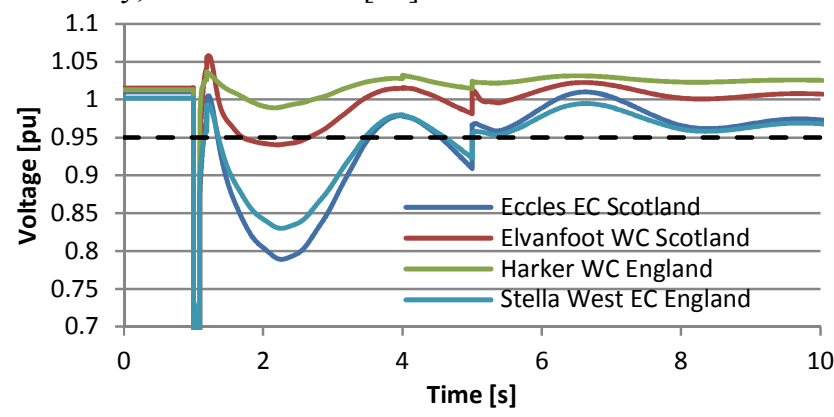

Fig. 12: AC connected wind farm at Location A: voltages at either end of the $\mathrm{EC}$ and WC circuits following a WC fault and a shunt reactor disconnected at the wind farm grid interface point after 5 seconds

In addition, the transient recovery voltage that appears across circuit breaker contacts when interrupting currents and the rate of rise of recovery of voltage should not exceed the capabilities of the circuit breaker, allowing it to successfully clear a fault. Both of these factors are influenced by the inductive and capacitive parameters on either side of the circuit breaker, the size of the fault current and type of fault. References [23][24] have shown that the highest overvoltage is at the onshore sending end of the cable in a load rejection study (where the wind farm is disconnected at the PCC and becomes islanded). As described in [23][24], investigations of the potential transient overvoltages due to faults within and without the wind farm transmission link, stochastic phased energisation of the export system and transformer inrush currents should be performed. This and the voltage step change limits noted in section II.A may result in the use of additional switchgear to allow energisation in stages, controlled switching (point on wave switching is commonly applied) or additional equipment to provide damping or current/voltage limitation. While this would entail additional cost, it would be small relative to, for example, the cable cost.

\section{ECONOMIC APPRAISAL}

As has been noted above, a key part of the comparison of an AC connection option with an HVDC option is the assessment of the requirement for reactive compensation and its capital cost, including that of offshore platforms on which to install it. In addition to the capital cost of equipment, other key elements of cost are those of maintenance and of losses.

\section{A. Capital costs}

Estimates of the reactive compensation required for Grid Code compliance for different sizes of wind farm and different lengths of cable connection are given in Tables II-IV. Platform-based mid-point compensation has been added only where necessary to facilitate sufficient active power export. Capital cost assumptions are given in Tables V and VI in the Appendix and are based on the values published in [16]. Where a range of costs is given in [16], the mid-point value of the range has been used. However, it is also noted that the costs of equipment are impacted significantly by market conditions, in particular the price of copper and vessel charter rates; the sensitivity of costs to these and other factors is discussed in [25].

TABLE II: INDUCTIVE REACTIVE COMPENSATION (MVAR) REQUIRED AT THE GIP TO ENSURE REQUIRED REACTIVE POWER CAPABILITY

\begin{tabular}{|l|r|r|r|r|}
\cline { 2 - 5 } \multicolumn{1}{c|}{} & \multicolumn{1}{c}{ 250MW } & 500MW & 1000MW & 1500MW \\
\hline $\mathbf{1 2 0} \mathbf{~ k m}$ & 205 & 410 & 821 & 1231 \\
\hline $\mathbf{1 6 0 k m}$ & 250 & 500 & 100 & 1501 \\
\hline $\mathbf{2 0 0} \mathbf{k m}$ & 235 & 470 & 939 & 1409 \\
\hline
\end{tabular}

TABLE III: INDUCTIVE REACTIVE COMPENSATION (MVAR) REQUIRED AT THE MID-POINT OF THE CABLES TO FACILITATE THE NECESSARY ACTIVE POWER TRANSFER

\begin{tabular}{|l|r|r|r|r|}
\cline { 2 - 5 } & \multicolumn{1}{|c|}{ 250MW } & \multicolumn{1}{c|}{ 500MW } & 1000MW & \multicolumn{1}{c|}{ 1500MW } \\
\hline $\mathbf{8 0 k m}$ & 0 & 0 & 0 & 0 \\
\hline $\mathbf{1 2 0} \mathbf{~ k m}$ & 0 & 0 & 0 & 0 \\
\hline $\mathbf{1 6 0 k m}$ & 151 & 301 & 602 & 903 \\
\hline $\mathbf{2 0 0 k m}$ & 194 & 388 & 776 & 1165 \\
\hline
\end{tabular}

TABLE IV: INDUCTIVE REACTIVE COMPENSATION (MVAR) REQUIRED AT THE WIND FARM BUS TO FACILITATE THE NECESSARY ACTIVE POWER TRANSFER

\begin{tabular}{|l|r|r|r|r|}
\cline { 2 - 5 } & \multicolumn{5}{|c|}{ 250MW } & 500MW & 1000MW & 1500MW \\
\hline $\mathbf{8 0} \mathbf{k m}$ & 108 & 216 & 431 & 647 \\
\hline $\mathbf{1 2 0} \mathbf{~ k m}$ & 171 & 342 & 682 & 1024 \\
\hline $\mathbf{1 6 0} \mathbf{k m}$ & 152 & 304 & 608 & 912 \\
\hline $\mathbf{2 0 0} \mathbf{k m}$ & 195 & 389 & 778 & 1168 \\
\hline
\end{tabular}

The capital costs involved with HVDC transmission include the costs of the voltage source converters at either end of the link and the cables. There are two different ways in which a HVDC VSC based transmission system can be arranged: monopole and bipole. Monopole entails a single VSC at either end with two cables between: positive and negative conductors. A bipole commonly has three cables, two poles and a metallic earth return, and two VSCs at each end allowing the voltage difference between the positive and negative poles to be doubled, facilitating double the power transfer [26]. The choice between different arrangements is driven by the desired power transfer capacity, cable voltage rating and the ability of the link to operate in a degraded state following a cable fault. To connect the $1000 \mathrm{MW}$ wind farm a bi-pole arrangement has been chosen with cable voltages of $\pm 300 \mathrm{kV}$. The PCC end VSCs are rated so that no more than the minimum power factor capability, as required by STC, is provided. 


\section{B. Operation and maintenance costs}

Operational costs have two primary sources: energy losses in the system and maintenance costs; together, these form a significant part of the lifetime cost of the transmission link. The primary source of losses in an AC transmission link is the cables although losses do also occur within the substations. The cost of compensating for the losses is treated as an operational cost to the transmission operator as extra generation must be dispatched to account for it in addition to the load to keep the system balanced.

Cable losses within the AC transmission link consist of two components: losses due to the reactive power production of the cable capacitance and losses due to the active power being transmitted. Both are a function of the cable resistance which itself comprises of components due to the conductor temperature, skin and proximity effects, armour and shield losses and cable length [25]. To calculate the losses in the cable the active and reactive components are each considered. It can be assumed that the capacitance of the transmission cable is evenly distributed along its length, and therefore it produces a certain amount of reactive power for every unit of length. However, the reactive power flow through each part of the cable is different. This is caused by the accumulation of the reactive power along the length of the cable which leads to it exporting reactive power to the MITS. Therefore the amount of reactive power flowing through the cable section closest to the MITS will be greatest and smallest at the wind farm end. The reactive power flow through different parts of the cable will be affected by the placement of reactive compensation at the wind farm end and at the cable mid-point, therefore this is also considered when determining the cable losses. The losses due to the active power transfer are calculated using the cable resistance and the current produced by the wind farm and are dependent on the wind speed. In addition, losses also occur within the transformers and reactive compensators; these comprise of no-load elements, $0.2 \%$ of nominal power flow, and load dependent elements, up to a maximum of $0.6 \%$ nominal power flow [27]. In this study $350 \mathrm{MVA}, 220 \mathrm{kV}$ three core AC cables with an $800 \mathrm{~mm}^{2}$ cross-section are used, which have a cable resistance of $0.06786 \mathrm{ohm} / \mathrm{km}$ (taking into account conductor temperature, skin and proximity effects and armour and shield losses) and a capacitance of $0.17 \mu \mathrm{F} / \mathrm{km}$ which produces a charging current of $6.9 \mathrm{~A} / \mathrm{km}[28]$.

The energy loss in the HVDC transmission link consists of two components: cable losses and conversion / substation losses. The cable losses are a function of the active power transfer and the cable resistance, whereas the conversion losses have a fixed no-load component as well as a component which is proportional to power flow. The HVDC cables used for the $1000 \mathrm{MW}$ and $500 \mathrm{MW}$ studies have the same diameter $\left(1800 \mathrm{~mm}^{2}\right)$ and therefore have a resistance of $0.0098 \mathrm{ohm} / \mathrm{km}$, whereas the cable used for the $250 \mathrm{MW}$ study has a diameter of $1200 \mathrm{~mm}^{2}$ with a resistance of $0.0151 \mathrm{ohm} / \mathrm{km}$ [29]. The converter losses are taken to be $0.16 \%$ of nominal power flow under no load, rising to $1.6 \%$ at full load, based on performance reported in [25] and [30] for a two-level converter. Although new installations might use multi-level
VSCs with lower losses, in this study converter loss represents between $27 \%$ and $42 \%$ of the total connection losses at full load for a $200 \mathrm{~km}$ connection. A reduction would therefore have a notable effect on the overall losses of the system, but would translate to a minor impact - around $1 \%$ - in the context of overall system cost including capital expenditure.

To determine the annual volume of energy lost, a distribution of the wind farm output power is required to give an indication of the amount of time the wind farm is operating at full output and at part output (in incremental steps). This is obtained using the probability distribution of the wind speed experienced by the wind farm and a power curve relating the wind speed to the output power [31]. The Weibull distribution with a shape parameter of 2.1 and a mean wind speed of $10 \mathrm{~m} / \mathrm{s}$ is used [32]-[34]. The $10 \mathrm{~m} / \mathrm{s}$ mean wind speed is determined using the European Wind Atlas for a wind farm located more than $100 \mathrm{~km}$ from shore, east of Scotland with a turbine hub height of more than $100 \mathrm{~m}$. The availability of the full wind farm capacity to produce power is also important. Operational experience with the first round of UK offshore wind farms indicates an availability of $80.2 \%$ [35].

The cost of compensating for the energy lost during transmission is calculated using an energy price of $£ 45 / \mathrm{MWh}$, which is an estimate of the average energy price at the time of the study [36]. Which party faces the cost of the losses depends on the location of the wind farm metering point. If it is at the WFB, the cost of transmission link losses is picked up by the transmission system operator. If it is at the PCC, the losses will represent lost revenue to the wind farm owner. The Offshore Transmission Owner (OFTO) regime in Britain requires the former [37]. However, if the latter were the case then the value of a Renewable Obligation Certificate (ROC), $£ 43.99$, must be added to the unit price of lost energy as the losses are effectively subtracted from the energy the wind farm supplies to the MITS [38]. The present ROC banding for an offshore wind farm is 1.5ROC/MWh generated [39].

In addition to the transmission losses, maintenance costs are a significant operational cost over the life-time of a transmission link. Submarine transmission cables, AC or HVDC, should require little maintenance so long as they are not damaged by a third party; however, the substation equipment requires regular maintenance. The nature of a substation situated on a platform potentially $200 \mathrm{~km}$ from shore introduces significant extra access costs regardless of transmission technology. While it can be asserted with confidence that remote offshore substations will be costly to maintain, there is, as yet, little publicly available information on the level of those costs and where estimates are published, they differ significantly. For example, [40] gives a lifetime maintenance cost for $\mathrm{AC}$ offshore substation equipment of $15 \%$ of its capital cost whereas [3] gives an annual maintenance cost of $0.5 \%$ of the capital costs for an HVDC substation. For the present analysis, $15 \%$ of the AC substation capital costs has been taken as the maintenance cost and broken down into annual components. $0.5 \%$ of the annualised HVDC substation capital cost is used in the HVDC case. 


\section{Comparison of total costs}

To allow comparisons to be drawn between the costs involved with each transmission technology, the lifetime costs are broken down over the expected life of the wind farm and transmission link ( 25 years) to give an annualised cost. To enable this, the effects of interest rates, perceived risk and depreciation of asset values are taken into account by calculating the capital recovery factor with a 25 year time frame and discount rate of $12 \%$. This discount rate is the mid-point of a range given for offshore wind given in [41].

The level of annual costs, as with each of the factors described above, are a function of the wind farm capacity. Fig. 13 shows the annual costs of connecting 250MW, 500MW and $1000 \mathrm{MW}$ wind farms using either transmission technology. It can be observed from this that the cross-over distance at which HVDC connection is cheaper than AC for the $500 \mathrm{MW}$ case occurs at a greater transmission distance than for the $1000 \mathrm{MW}$ wind farm. This is primarily due to the proportionally larger capital costs involved with HVDC and the value of the losses in the AC cables being a lot less. For the 250MW case, the capital costs of the HVDC technology are sufficiently dominant to prevent it becoming the cheapest option at any of the transmission distances studied here.

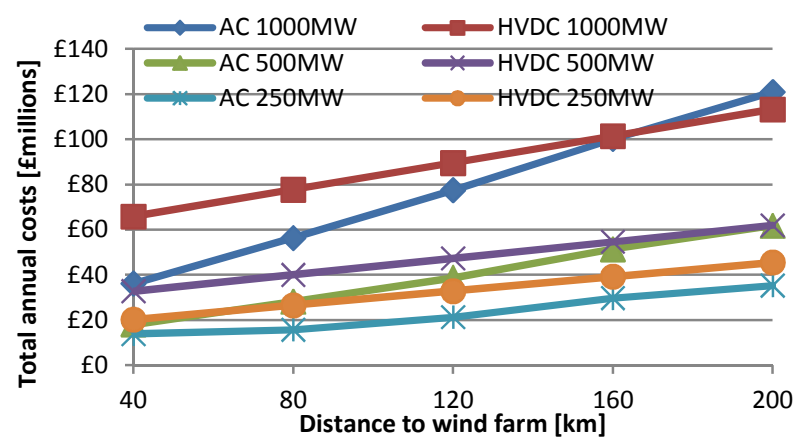

Fig. 13: Total annual costs of $250 \mathrm{MW}, 500 \mathrm{MW}$ and $1000 \mathrm{MW}$ transmission links using AC or HVDC technology over different transmission distances

The figures calculated here are highly dependent on system design assumptions and the arrangement of the renewable obligation incentive regime in the GB. To provide an insight into how sensitive the economic analysis is to these assumptions three sensitivity studies have been conducted: (1) where the opportunity cost of the ROCs that are lost due to transmission losses is included in the cost of energy (Fig. 14); (2) where the metallic earth return is removed from the 1000MW HVDC bipole system saving on both cable and installation cost (Fig. 15); (3) where a STATCOM is included at the PCC in the AC case to provide the continuous voltage control capability, which the STC implies is required. (For brevity, this result is not shown graphically). It can be observed from Fig. 14 that the cross-over between costs of the two technologies occurs at a shorter transmission distance for the $1000 \mathrm{MW}$ and $500 \mathrm{MW}$ cases, indicating that the AC transmission costs are more sensitive to the cost associated with losses than HVDC transmission. Also, in Fig. 15 a similar result is observed where the cross-over reduced to $120 \mathrm{~km}$, indicating that the omission of the metallic earth return could be preferable from an economic point of view, although the potential impact of the inability to still operate in the event of a fault on one cable is not considered in these calculations. Lastly, for a 1000MW wind farm with the meter at the WFB, the cross-over distance reduces from $160 \mathrm{~km}$ to $120 \mathrm{~km}$ if a STATCOM is used to provide the PCC reactive compensation.

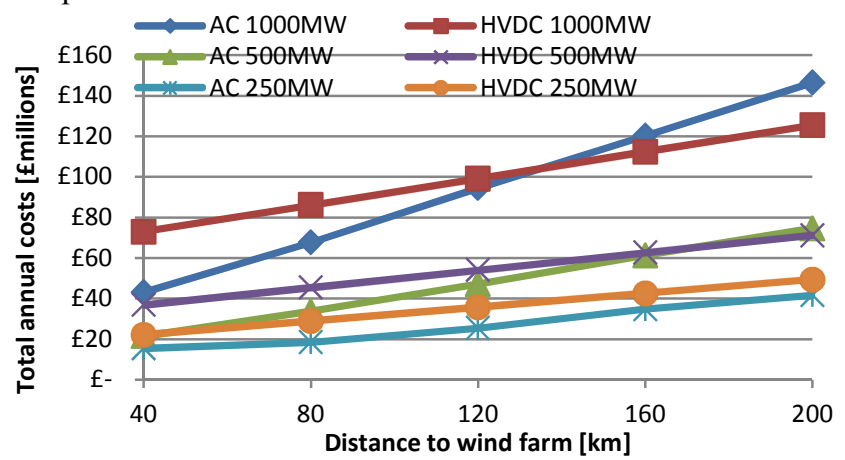

Fig. 14: Total annual costs of 250MW, 500MW and 1000MW transmission links using AC or HVDC technology over different transmission distances, where the cost of lost ROCs is included in the cost of lost energy.

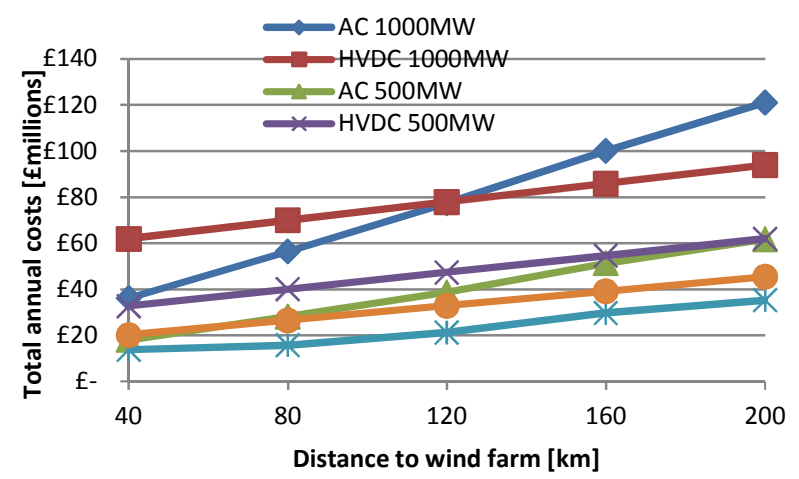

Fig. 15: Total annual costs of 250MW, 500MW and 1000MW transmission links using AC or HVDC technology over different distances, where the earth return cable has been omitted from the 1000MW HVDC option.

By way of comparison, for a 200MW-500MW offshore wind farm [2] with different lengths of cable connection, cross-over distances of $35 \mathrm{~km}-80 \mathrm{~km}$ are reported in different scenarios.

\section{Developer incentives}

To date in Britain, offshore wind farm developers have constructed the transmission link connecting their wind farm to the MITS and then sold it to an OFTO once it is operational. In such a situation and where the wind farm output metering point is at the wind farm bus, in evaluating different connection options, as far as the authors of this paper understand, there is little incentive for the wind farm developer to consider the potential volume of energy lost during transmission as this will not affect the revenue earned by the wind farm. As a consequence, the wind farm developer would likely be inclined to opt for the means of providing the transmission link between the wind farm and the MITS that has the lowest capital cost regardless of whether the overall lifetime cost - capital cost plus losses - was lower. This could result in the costs incurred by the system operator, to compensate for transmission losses, being higher than would otherwise be the case and a higher total cost. 


\section{CONCLUSIONS}

This study has investigated the technical and economic characteristics of two transmission technologies (AC and HVDC) that could be used for the connection of an offshore wind farm to the main interconnected transmission system (MITS) in Britain and described the influence of industry codes on a connection design and, hence, cost.

The analysis of the steady state characteristics of $\mathrm{AC}$ transmission has highlighted the importance of considering the reactive power production of a long AC submarine cable and how it affects active power carrying capability and voltage profile along the cable length. It has been shown that use of inductive reactive compensation at both ends of an $\mathrm{AC}$ cable connection and, where necessary, also the cable mid-point can release cable thermal capacity for the transfer of active power. An investigation of the dynamic characteristics of both the AC and HVDC transmission technologies in response to short circuit faults on the MITS has then been conducted using a model of the full GB transmission system. While the analysis presented here is limited, it does suggest that both approaches can comply with industry standards in a context that is known to be stability limited, albeit that further work may reveal benefits, e.g. in respect of system damping, arising from supplemental controls on an HVDC link or on an SVCs or STATCOM associated with an AC connection.

In addition to the technical investigations that have been conducted, an analysis of the economic characteristics of using either technology to connect the wind farm has been performed where it is noted that, as a minimum, the cost of equipment necessary to comply with relevant standards must be included. In respect of an AC connection, this includes reactive compensation. The analysis has determined the capital and operational costs of both technologies to give a comparison as the transmission distance is increased for different sizes of wind farm. For the HVDC option, capital costs associated with the VSCs are highly significant while the costs associated with the energy lost during transmission are substantially larger for the AC option deployed for a long distance than for the HVDC option. These two aspects combine to give a cross-over where the annual costs of using $\mathrm{AC}$ transmission becomes greater than those associated with using HVDC transmission at an approximate transmission distance of between $120 \mathrm{~km}$ and $160 \mathrm{~km}$ for a $1000 \mathrm{MW}$ wind farm, the shorter distance being for the case when reactive compensation in the AC case is provided by STATCOM or a metallic earth return is omitted from the HVDC design.

Wind farm capacity has a significant impact on the location of the cross-over between the annual costs of using AC and HVDC transmission technologies; indeed, it has been shown for a wind farm capacity of $250 \mathrm{MW}$ that, over the range of transmission distances studied, AC transmission has the lowest cost and for a $500 \mathrm{MW}$ wind farm the cross-over is approximately $200 \mathrm{~km}$. A trend therefore emerges between the wind farm capacity and the transmission distance at which HVDC becomes the cheaper transmission technology: the higher the wind farm capacity and therefore the required transmission capacity, the shorter the transmission distance where the cross-over occurs.

As a final remark, an AC option should be studied in more detail in respect of a number of technical considerations that have not been considered fully here. In particular, remedial measures may need to be introduced to limit transient over voltages during both controlled and uncontrolled operations. Furthermore, for both AC and HVDC options, the possibility of harmonic resonances having been introduced should be checked and damping circuits introduced if necessary.

\section{APPENDIX}

TABLE V: ASSUMED CAPITAL COSTS FOR AC CONNECTION [16]

\begin{tabular}{|l|l|l|}
\hline Component & Cost & $\begin{array}{l}\text { Notes, e.g. for 1000MW } \\
\text { wind farm }\end{array}$ \\
\hline $\begin{array}{l}\text { 350MVA 220kV 3-core, } \\
\text { submarine cable }\end{array}$ & $£ 470 \mathrm{k} / \mathrm{km}$ & $\begin{array}{l}\text { 4 parallel cables with length } \\
\text { increasing with distance to } \\
\text { wind farm. }\end{array}$ \\
\hline $\begin{array}{l}\text { Cable installation of 2 } \\
\text { cables in one trench at 1m } \\
\text { depth }\end{array}$ & $\begin{array}{l}£ 675 \mathrm{k} / \mathrm{km} / \\
\text { trench with 2 } \\
\text { cables }\end{array}$ & 4 cables require 2 trenches. \\
\hline $\begin{array}{l}\text { Onshore GIS switchgear } \\
\text { (275kV and 400kV). }\end{array}$ & $\begin{array}{l}£ 2.1 \text { million / } \\
275 \mathrm{kV} \\
\text { substation } \\
£ 2.6 \mathrm{million} / \\
400 \mathrm{kV} \\
\text { substation }\end{array}$ & $\begin{array}{l}\text { Required for either side of } \\
\text { GIP transformers. }\end{array}$ \\
\hline $\begin{array}{l}\text { 220kV/400kV 275MVA } \\
\text { transformer. }\end{array}$ & $\begin{array}{l}£ 2.34 \text { million / } \\
\text { transformer }\end{array}$ & $\begin{array}{l}\text { 1053MVA capacity is } \\
\text { required to transfer 1000MW } \\
\text { at 0.95 pf, hence 4 } \\
\text { transformers required. }\end{array}$ \\
\hline $\begin{array}{l}\text { 500MW 220kV/33kV } \\
\text { Offshore substation, }\end{array}$ & $\begin{array}{l}£ 39.1 \text { million / } \\
\text { including 500tonne } \\
\text { platform, 220kV GIS } \\
\text { switchgear, jacket } \\
\text { foundation and installation } \\
\text { in 20-30m water depth. }\end{array}$ & $\begin{array}{l}\text { A single platform would } \\
\text { most likely be used; therefore } \\
\text { the costs have been scaled } \\
\text { linearly to give 1000MW } \\
\text { capacity. }\end{array}$ \\
$\begin{array}{l}\text { Mechanically switched } \\
\text { shunt reactors 100MVar at } \\
\text { 220kV. }\end{array}$ & $\begin{array}{l}£ 1.2 \mathrm{million} / \\
100 \mathrm{Mvar}\end{array}$ & $\begin{array}{l}\text { Required at GIP, cable mid- } \\
\text { point and WFB, depending } \\
\text { on cable length }\end{array}$ \\
\hline
\end{tabular}

TABLE VI: ASSUMED CAPITAL COSTS FOR HVDC CONNECTION [16]

\begin{tabular}{|c|c|c|}
\hline Component & Cost & $\begin{array}{l}\text { Notes, e.g. for } 1000 \mathrm{MW} \text { wind } \\
\text { farm }\end{array}$ \\
\hline $\begin{array}{l}500 \mathrm{MW} 300 \mathrm{kV} \\
\text { HVDC } 1800 \mathrm{~mm}^{2} \\
\text { single core cable. }\end{array}$ & $£ 360 \mathrm{k} / \mathrm{km}$ & $\begin{array}{l}3 \text { parallel cables required for } \\
\text { positive and negative poles and } \\
\text { metallic earth return with length } \\
\text { increasing with distance to wind } \\
\text { farm. (earth return cable is } \\
\text { assumed to be same as pole } \\
\text { cables) }\end{array}$ \\
\hline $\begin{array}{l}\text { Installation of cables } \\
\text { at } 1 \mathrm{~m} \text { depth. }\end{array}$ & $\begin{array}{l}£ 675 \mathrm{k} / \mathrm{km} / \\
\text { trench with } 2 \\
\text { cables } \\
£ 400 / \mathrm{km} / \\
\text { trench with } \\
\text { single cable }\end{array}$ & $\begin{array}{l}3 \text { cables, } 2 \text { buried in a single } \\
\text { trench and one cable in a second } \\
\text { trench. }\end{array}$ \\
\hline $\begin{array}{l}\text { Shore end 550MVA } \\
\text { 300kV Voltage Source } \\
\text { Converter (VSC), } \\
\text { inc.AC switchgear. }\end{array}$ & $\begin{array}{l}\text { £68million / } \\
\text { converter }\end{array}$ & $\begin{array}{l}2 \mathrm{VSCs} \text { are required giving }+/- \\
300 \mathrm{kV} \text {. }\end{array}$ \\
\hline $\begin{array}{l}150 \mathrm{kV} / 400 \mathrm{kV} \\
275 \mathrm{MVA} \text { transformer, } \\
\text { inc. } 400 \mathrm{kV} \text { GIS } \\
\text { switchgear }\end{array}$ & $\begin{array}{l}£ 2.34 \text { million / } \\
\text { transformer } \\
£ 2.6 \text { million / } \\
\text { 400kV GIS } \\
\text { substation }\end{array}$ & $\begin{array}{l}1053 \mathrm{MVA} \text { capacity is required to } \\
\text { transfer } 1000 \mathrm{MW} \text { at } 0.95 \mathrm{pf} \text {, } \\
\text { therefore } 4 \text { transformers are } \\
\text { required. }\end{array}$ \\
\hline
\end{tabular}




\begin{tabular}{|c|c|c|}
\hline Component & Cost & $\begin{array}{l}\text { Notes, e.g. for } 1000 \mathrm{MW} \text { wind } \\
\text { farm }\end{array}$ \\
\hline $\begin{array}{l}\text { Offshore VSC } \\
\text { platform inc. } 2 x \\
500 \mathrm{MW} \text { VSCs and } \\
220 \mathrm{kV} \text { GIS } \\
\text { switchgear, including } \\
8000 \text { tonne platform, } \\
\text { jacket foundation and } \\
\text { installation in } 20-30 \mathrm{~m} \\
\text { water depth. }\end{array}$ & $\begin{array}{l}£ 232 \text { million / } \\
\text { platform }\end{array}$ & $\begin{array}{l}\text { Single platform for bi-pole VSCs } \\
\text { and AC switchgear. }\end{array}$ \\
\hline
\end{tabular}

\section{ACKNOWLEDGEMENTS}

The support of Scottish Power Energy Networks in the execution of the full GB system transient stability analyses is gratefully acknowledged.

\section{REFERENCES}

[1] National Grid Electricity Transmission (2015, Feb). Electricity Ten Year Statement 2013, Available http://www2.nationalgrid.com/UK/Industryinformation/Future-of-Energy/Electricity-ten-year-statement/Currentstatement/

[2] Lazaros P. Lazaridis, Economic Comparison of HVAC and HVDC Solutions for Large Offshore Wind Farms under Special Consideration of Reliability, Master's Thesis, Royal Institute of Technology, Department of Electrical Engineering, Stockholm 2005.

[3] B. Van Eeckhout, et al., "Economic comparison of VSC HVDC and HVAC as transmission system for a $300 \mathrm{MW}$ offshore wind farm", European Transactions on Electrical Power, 20(5): p. 661-671, 2010.

[4] N. Barberis Negra, J. Todorovic and T. Ackermann, "Loss Evaluation of HVAC and HVDC Transmission Solutions for Large Offshore Wind Farms", Electric Power Systems Research, July 2006.

[5] Ranjan Sharma, Tonny W. Rasmussen, Kim Høj Jensen, Vladislav Akamatov, "Modular VSC Converter Based HVDC Power Transmission from Offshore Wind Power Plant: Compared to the Conventional HVAC System", 2010 IEEE Electrical Power \& Energy Conference (EPEC), Halifax, 25 Aug - 27 Aug 2010.

[6] ABB, (2015, Feb). Offshore Wind Connections, Available: http://new.abb.com/systems/hvdc/offshore-wind-connectionsed

[7] Siemens. (2015, Feb). "Siemens successfully installs fourth HVDC platform in the North Sea for TenneT", Available: http://www.siemens.com/press/en/feature/2013/energy/2013-08-xwin.php?content []$=$ E\&content []$=$ ES\&content []$=$ ET\& content []$=$ EW\&sto p_mobi $=$ true

[8] ABB, (2015, Feb). "World's longest, most powerful dynamic AC cable Goliat floating oil and gas platform, Barents Sea", 2013, available http://www05.abb.com (accessed 11/11/2014)

[9] ABB, (2015, Feb). "World's first power-from-shore dynamic AC cable Gjoa floating oil and gas platform, North Sea", 2010, Available http://www05.abb.com

[10] KIS-ORCA. (2015, Feb). Manx Cable Company - Isle of Man to England Interconnector, Manx Cable Company - Isle of Man to England Interconnector, Available http://www.kis-orca.eu/operators/subseacable/manx-cable-company\#.VGJZlsmfvqw

[11] W. Wiechowski and P. B. Eriksen, "Selected studies on offshore wind farm cable connections - challenges and experience of the Danish TSO", IEEE Power and Energy Society General Meeting, 2008.

[12] 4COffshore, (2015, Feb). BorWin Alpha (NOR-6-1 in O-NEP) Converter, http://www.4coffshore.com/windfarms/hvdc-converterborwin-alpha-\%28nor-6-1-in-o-nep\%29-cid1.html

[13] National Grid Electricity Transmission Plc, (2015, Feb). The Grid Code, 2013, Available http://www2.nationalgrid.com/UK/Industryinformation/Electricity-codes/Grid-Code

[14] National Grid Electricity Transmission, (2015, Feb). The System Operator Transmission Owner Code, 2014, Available http://www2.nationalgrid.com/UK/Industry-information/Electricitycodes/System-Operator-Transmission-Owner-Code

[15] National Grid Electricity Transmission Plc, (2015, Feb). National Electricity Transmission System Security and Quality of Supply Standard, 2012, Available http://www2.nationalgrid.com/UK/Industryinformation/Electricity-codes/SQSS/The-SQSS
[16] National Grid Electricity Transmission, Offshore Development Information Statement, 2010.

[17] Smart Wind, Round 3 Hornsea Zone - Development Update - Project Preliminary Environmental Information Summary, 2012.

[18] C. Zhang, "Developing Efficient \& Secure Grid Connection in Deeper Waters, Further Offshore by Optimising Electrical Design \& Transmission Technologies", Deeper Water Offshore Wind Conference - Lowering Costs Together. 2013.

[19] DiGSILENT, (2015, Feb). PowerFactory - DIgSILENT Germany, available http://www.digsilent.de/index.php/products-powerfactory.html

[20] Enslin, J.H.R., H. Yi, and R. A.Wakefield, "System Considerations and Impacts of AC Cable Networks on Weak High Voltage Transmission Networks", IEEE Transmission and Distribution Conference and Exhibition, 2006

[21] L. Colla, S. Lauria, and F.M. Gatta, "Temporary overvoltages due to harmonic resonance in ling EHV cables", International Conference on Power Systems Transients (IPST), 2007.

[22] R. Hodges, S. Dixon, and G. Bathurst, "Management of low frequency resonances for large scale offshore wind power plants with long AC cable connections", 12th Wind Integration Workshop, London, 2013.

[23] O. Nanka-Bruce, et al., "TRV Investigations to assess the suitability of $132 \mathrm{kV}$ circuit breakers for an offshore wind farm connection", International Conference on Power Systems Transients, Kyoto, Japan, 2009.

[24] K. L. Koo, et al., "Triton Knoll offshore wind power plant transient studies: Modelling and study of long AC cable systems and reactor Compensation for a grid connection", 12th Wind Integration Workshop, London, 2013.

[25] B. Van Eeckhout, The economic value of VSC HVDC compared to HVAC for offshore wind farms, Katholieke Universiteit Leuven, 2008.

[26] Friends of the Supergrid, Roadmap to the Supergrid Technologies Update Report, 2013

[27] H. Brakelmann, "Efficiency of HVAC power transmission from offshore-windmills to the grid", IEEE Bologna PowerTech, 2003.

[28] ABB, XLPE Submarine Cable Systems - Attachement to XPLE Land Cable Systems -Users guide (rev 5)

[29] ABB, "It's time to connect - Technical description of HVDC light technology", 2008.

[30] ABB. Estlink-Connecting Estonia to the Nordic network. Available: http://library.abb.com.

[31] J.R. McLean, TradeWind WP2.6 - Equivalent Wind Power Curves, EWEA, 2008.

[32] T. Burton et al, The Wind Energy Handbook. Vol. 1. Wiley, 2008.

[33] J. P. Coelingh, A. J. M. Van Wijk, and A. A. M. Holtslag, "Analysis of wind speed observations over the North Sea", Journal of Wind Engineering and Industrial Aerodynamics, 1996. 61(1): p. 51-69, 1996.

[34] Windatlas (Nov. 2013)/ European wind resources over open sea. Available: http://www.windatlas.dk/europe/oceanmap.html

[35] Feng, Y., P.J. Tavner, and H. Long, "Early experiences with UK Round 1 offshore wind farms", Proceedings of the Institution of Civil Engineers: energy, 163, 2010.

[36] Elexon. (Feb. 2015). Balancing mechanism reporting system, Available: http://www.bmreports.com/

[37] S. McGregor, "UK's Offshore Transmission Regime : A case study for financing a low carbon future", Cambridge University Energy Network Annual Conference, 2011.

[38] ePower, (Feb. 2015). E-ROC Online ROC Auction Service. Available: $\mathrm{http}: / /$ www.epowerauctions.co.uk/index.htm .

[39] DECC, (Feb. 2015). Renewable Obligation Certificate (ROC) Banding. 2013. Available: https://www.gov.uk/calculating-renewable-obligationcertificates-rocs

[40] Econnect, Study on the development of the offshore grid for connection of the round two wind farms, 2005

[41] Oxera, Discount rates for low-carbon and renewable generation technologies, 2011. 


\section{BIOGRAPHIES}

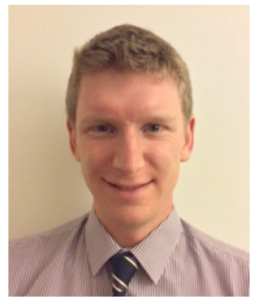

Douglas Elliott gained his $\mathrm{PhD}$ from the University of Strathclyde in 2014 where he was part of the EPSRC funded Centre for Doctoral Training in Wind Energy Systems. His thesis focuses on investigating alternative electrical systems for offshore wind farms that provide cost savings and enhanced reliability, in particular looking at the application of DC interturbine collector networks. He is a member of the IET and also holds an MEng in Electrical Energy Systems from the University of Strathclyde. Douglas joined Siemens Wind Power in the spring of 2014 as a Development Engineer in the Frequency Converter Centre of Competency, based in the UK.

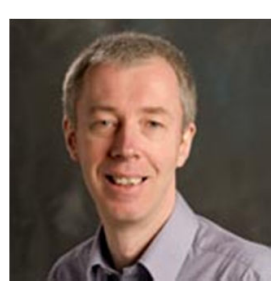

Keith Bell is the ScottishPower Professor of Smart Grids at the University of Strathclyde. He joined the University in 2005 having previously gained his $\mathrm{PhD}$ at the University of Bath and worked as an electrical engineering researcher in Manchester and Naples, and as a system development engineer in the electricity supply industry in Britain. He is Chartered Engineer, a co-Director of the multi-disciplinary UK Energy Research Centre (UKERC), an invited expert member of CIGRE Study Committee $\mathrm{C} 1$ on System Development and Economics and a member of the Council of the IET Power Academy, an initiative to promote electric power engineering as a graduate career in the UK.

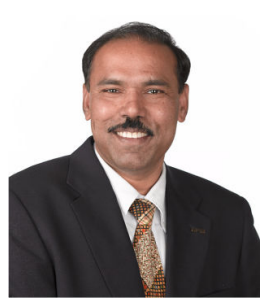

Dr. Ram Adapa is a Principal Technical Leader in the Transmission and Substations area of the Power Delivery and Utilization Sector at EPRI, Palo Alto, CA, USA. His research activities focus on High Voltage Direct Current (HVDC) transmission, Flexible AC Transmission Systems (FACTS), Fault Current Limiters, dynamic circuit ratings to increase transmission capacity, and transmission system reliability performance metrics. Before joining EPRI in 1989, Dr. Adapa worked at McGrawEdison Power Systems (presently known as Cooper Power Systems) as a Staff Engineer in the Systems Engineering Department. Dr. Adapa is an IEEE Fellow and has been honored several times by the IEEE for his outstanding contributions to the profession. He has authored or coauthored more than 125 technical papers and is an IEEE Distinguished Lecturer. He is an individual member of CIGRE, Technical Advisor of IEC TC115 - HVDC Transmission Standards development, and a Registered Professional Engineer.

Cornel Brozio is Design Analysis Manager at ScottishPower Energy Networks based in Glasgow, UK. Before completing his Ph.D at the University of Stellenbosch in 1999, he worked for Eskom, South Africa. He joined National Grid, UK in 1999 and ScottishPower in 2003, where he heads up a team responsible for a broad range of network analysis and simulation activities and has contributed to wide range of transmission system projects including HVDC and series compensation projects. $\mathrm{He}$ is a Chartered Engineer and is a member of the IET and the IEEE.

James $\mathbf{Y u}$ is Transmission Innovation Lead with ScottishPower Energy Networks based in Glasgow, UK. He gained an MSc in Power Systems from the University of Newcastle-Upon-Tyne and a $\mathrm{PhD}$ in wind power generation from Northumbira University. Prior to joining SP Energy Networks, he worked as a transmission planner with Scottish Hydro Electric Transmission Limited.

Khadim Hussain is a Senior Power Systems Engineer with National Grid Electricity Transmission based in Warwick in the UK. He joined National Grid in 1998 after some years with Westinghouse and Schneider in in the UK, a period with SCECO in Saudi Arabia and 6 years in the nuclear industry in Britain. He is Chartered Engineer and is a Member of IET, IEEE and CIGRE. He has Worked on a number of projects on generation and transmission networks - power system design, planning, analysis and control studies, AC/DC interconnectors, FACT devices, substations, series compensation \& SSR, control centres, energy management systems - off-line and real-time power applications software including simulators, nuclear power stations performance analysis, control systems, renewable energy, Smart Grid, and demand side management. 